\title{
Study of Novel Separation Technique "Pervaporation" for Separation of Acetronitrile and Tetrahydrofuran from waste Stream
}

\author{
Isha Meshram \\ M. Tech Scholar, Department of Chemical Engineering, Vishwakarama Institute of Technology, Pune, \\ Maharashtra, India
}

\begin{abstract}
Article Info

Volume 8, Issue 4

Page Number : 698-703

\section{Publication Issue}

July-August-2021

\section{Article History}

Accepted : 07 Aug 2021

Published : 14 Aug 2021

Pervaporation is a very effective membrane process for the separation of liquid mixtures. Due to its economics, efficiency and simplicity, it can easily be integrated into the distillation and rectification processes and, depending on the specific operating parameters, even partially replace them. Pervaporation technology can effectively recovery acetonitrile from the waste stream and separate a tetrahydrofuran (THF) solvent-water waste stream. Pervaporation technique was used for the mixture of close boiling point and to break the azeotrope in the most economical way. The combination of Distillation columns and pervaporation unit were used for recovery of acetoniritle which was not TDS process and was economically feasible for larger stream. This technique used is economical and energy efficient for the separation.

Keywords : Pervaporation, Azeotrope Mixture, Membrane, Acetonitrile, Tetrahydrofuran
\end{abstract}

\section{INTRODUCTION}

Pervaporation is an advance separation technique for separating mixtures which were difficult to separate. It's an energy intensive, economical, safer and a green separation technology. The phenomenon of 'pervaporation' was first perceived by Kober in 1917. The usefulness for separation and concentration was recognized in 1935 by Farber. Membrane technology at that time could not produce high performance membranes and modules required for commercially processes. Between 1973 to 1980s, many patents were assigned to Monsanto for covering wide application of pervaporation. However, none of this work led to commercialization, but in 1980s, advances in membrane technology made it possible to prepare economically viable pervaporation systems for separation of mixture which were never done. Distillation-Pervaporation Hybrid Systems are an alternate to separate azeotropic mixtures, since pervaporation isn't limited by the liquid-vapor equilibrium as distillation. Different unit operation techniques like adsorption, extractive distillation, distillation of azeotropic mixtures and liquid-liquid extraction are utilized in chemical engineering practices for the separation of such mixtures. But 
conventional separation techniques use extensive amounts of energy, external entertainer and downstream processing to recover key component and also these techniques often contaminate the product and creates environmental pollution. It's a cheap, energy saving and safe membrane separation technique which is efficient to try to to separation at normal operating conditions without using any external chemical separating agent or the other downstream processing. Industrial growth is usually related to exponential energy demands and a more precise control on the environmental pollution. Pervaporation technique is successfully in fulfilling these requirements to conserve the energy and to protect the environment. Pervaporation may be a membrane separation process conducted by partial vaporization employing a nonporous membrane. The driving forces which cause the transport of liquid through the selective membrane are chemical potential difference, partial pressure difference and membrane transport rate. The Membrane is a selective transport barrier during the separation of solute from the majority solvent. PV Process "A Green Separation Process": Green Separation Processes are a universally accepted term getting used worldwide just for those processes which are environmentally friendly. It doesn't need any hazardous or toxic chemicals for separation, it doesn't discharge any hazardous effluent stream, it's not getting to become a neighborhood of worldwide warming, no air, water or ground pollution involved within the process, a noise free process.

\section{MATERIAL}

Acetonitrile, often abbreviated $\mathrm{MeCN}$ (methyl cyanide), is that the compound with the formula $\mathrm{CH} 3 \mathrm{CN}$. This colourless liquid is that the simplest organic nitrile. It's produced mainly as a byproduct of acrylonitrile manufacture. Acetonitrile is employed mainly as a solvent within the refineries. Acetonitrile may be a byproduct within the production of acrylonitrile and its production also decreased, further compounding the acetonitrile shortage. The worldwide shortage of acetonitrile continued.

Tetrahydrofuran, THF, is a heterocyclic compound with oxygen. The molecular formula for THF is (CH2)4O. Its low boiling point also makes it easy to remove from chemical reactions by evaporation. Since the speciality solvents are not consumed in the reaction stoichiometry, they end up as waste, which must be either disposed or recycled. The cost of the virgin solvent is very high and waste solvent increases the manufacturing cost much higher. Therefore, there is need for recovery and reuse the solvent.

\section{METHOD/PROCESS}

There were two method of recovery were done separately for acetonitrile and tetrahydrofuran which were mainly used

\subsection{Distillation of Acetonitrile and Tetrahydrofuran}

3.2. Dehydration/Purification of Acetonitrile and Tetrahydrofuran

\subsection{Distillation of Acetonitrile and Tetrahydrofuran}

As the feed for two separate distillation column was the mixture of Acetonitrile and wastes tream and Tetrahydrofuran and waste stream. So both the mixture was Azeotropic. Almost extractive distillation column with pressure swing was used to break the azetrope of both mixtures. Benzene as an entrainer was used to break the complex azeotrope mixture. Due to this the overall process became very complex. Electricity consumption is slightly higher for the pressure swing, as expected due to the presence of an additional pump. Higher steam cost is observed for pressure swing, due to the need of higher pressure steam for the higher temperature achieved in the reboiler of the high pressure column. Hence the cost of the production, investment cost, operating cost has been increased a lot and as noticed there was a lot of wastage of energy. Therefore the distillation process 
was not much effective for the recovery of both acetonitrile and tetrahydrofuran from the waste stream.

\subsubsection{Process for Recovery of Acetonitrile}

In "Fig. 1" A waste feedstock containing approximately $89.9 \mathrm{wt} \%$ ACN, methanol, and other contaminants was introduced in the distillation column. It is appreciated that the acetonitrile feedstock may contain more or fewer constituents. Based on the known binary azeotropic and normal pure component boiling temperatures, all of the acetonitrile azeotrope and benzene are rectified to produce a column outlet vapor stream and the vapor is condensed within the condenser. The product from the condenser is sent to pervaporation where two layers are produce, a bottom layer containing methanol and a top layer of ACN. The retenate from top is send to 2nd distillation column from where bottom product is ACN and the impurities or traces of methanol is again recycle to 1st distillation column. The bottom product of the 1st distillation column is water

Purities of the ACN in stream can be at least $98 \mathrm{wt} \%$ and up to 99.97 wt.\%.

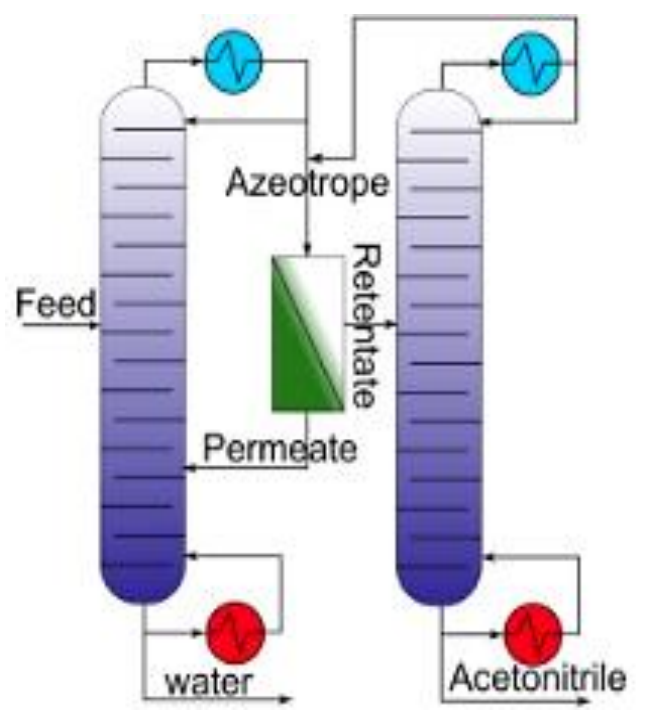

Figure 1 : Recovery of acetronitrile from waste stream

\subsubsection{Process for Recovery of Tetrahydrofuran}

In "Fig. 2" The dehydration of a Tetrahydrofuranwater mixture was studied on the lab scale near the standard, atmospheric azeotrope conditions. The binary feed mixture of Tetrahydrofuran/water has an azeotropic behavior, existing at $4.3 \mathrm{wt} \%$ water. The feed concentration range is limited to concentrations higher than $70 \mathrm{wt} \%$ Tetrahydrofuran. A pressure range is established due to limitation in the equipment, and lack of substantial permeate Feed in the heat exchanger is has allow to flow in system to cool to room temperature of approx. The fluid leaving the membrane in the permeate stream, and then collected vapor, was condensed.

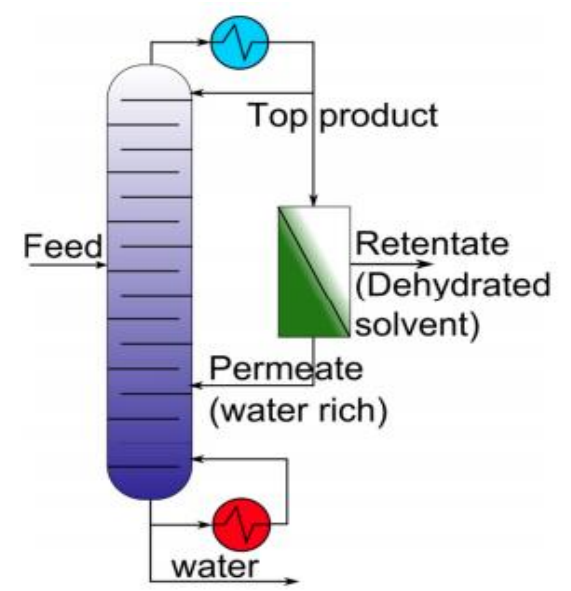

Figure 2 : Recovery of tetrahydrofuran from waste stream

\section{RESULTS AND DISCUSSION}

The discussion and result of the pervaporation process for acetonitrile and tetrahydrofuran are discussed below. The effect of the permate on pressure and temperature can be seen with the help of the graph and which is studied in detail below.

\subsection{EFFECT OF PERMEATE ON PRESSURE}

Permeate pressure effect was studied by increasing pressure on the permeate side. The maximum permeate pressure used because beyond this, the 
driving force across the membrane is not sufficient enough to transport a measurable amount of water the permeate pressure is increased due to the pressure driving through. A considerable decrease in flux can be seen as force. Flux is dependent on the difference in partial pressures of each component for both the feed and permeates sides of the membrane, as well as membrane thickness. In "Figure 3"the effect of temperature on permeate flux for dehydration using PVA membrane and silica ceramic membrane at 10 torr absolute permeate pressure, and $95 \& 96 \mathrm{wt} \%$ feed composition. Total Flux for PVA $(\downarrow)$, Water Flux for PVA (曰), Total Flux for Silica (•), Water Flux for Silica (X). When a PVA membrane is used, permeate pressure is increased, total flux decreases from in a linear fashion. Water flux also decreased in a similar linear fashion, all values being only slightly less than total flux since the average permeates composition is $94 \mathrm{wt} \%$ water. The flux varied only slightly in this study.
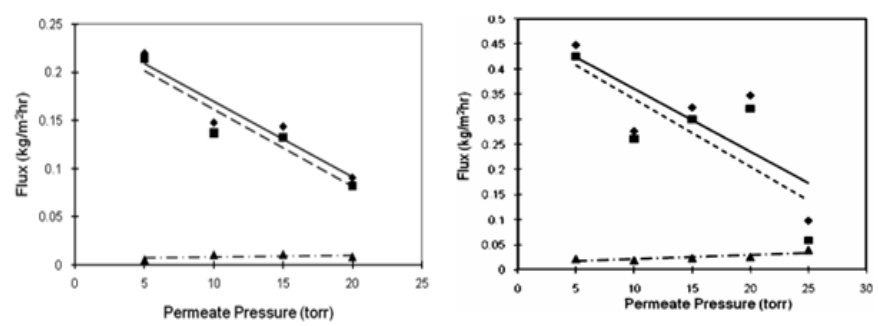

Figure 3: The effect of temperature on permeate flux

\subsection{EFFECT OF PERMEATE ON TEMPERATURE}

The effect of temperatures was studied and membrane performance is highly dependent on temperature, and is enhanced as the temperature is increased. Feed temperature effects the membrane permeability coefficient and the driving force for mass transfer. An exponential increase of total flux with increasing feed temperature. Permeability is a function of solubility and diffusivity coefficients of the permeants in the membrane that are exponentially dependant on temperature. Flux dependence on temperature for polymer and ceramic membranes, are shown respectively. In "Figure 4" the effect of temperature on permeate flux for dehydration using PVA membrane and silica ceramic membrane at 10 torr absolute permeate pressure, and 95 \& $96 \mathrm{wt} \%$ feed composition. Total Flux for PVA ( $)$, Water Flux for PVA (ㅁ) , Total Flux for Silica $(\cdot)$, Water Flux for Silica $(\mathrm{X})$.The total and component fluxes are shown on the graphs, all exhibiting exponential trend. For the PVA membrane, as the temperature was increased, the total flux rapidly increases and water flux had a similar correlation of exponential increase the composition of the permeate was primarily water, the flux was quite low, and is the variable least affected by temperature. While using silica membrane as temperature was raised, total flux increased rapidly.
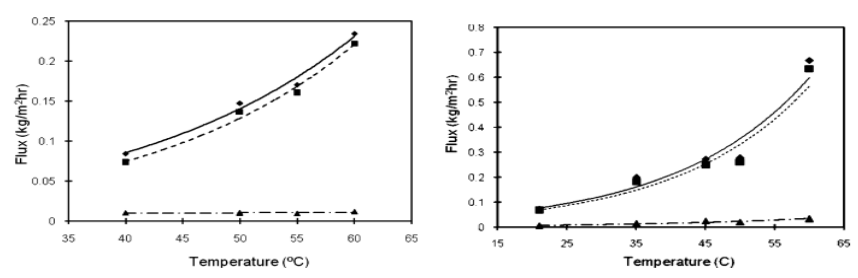

Figure 4: The effect of temperature on permeate flux

\subsection{Result}

The membrane performance for both Acetonitrile and Tetrahydrofuran was studied in detail in 4.4.1 and 4.4.2. Studies were conducted with polymeric and ceramic membranes to analyze the effect of feed temperature and permeate pressure on pervaporative performance which can further seen in "Table 1 and Table 2".

\subsubsection{Membrane Performance for Tetraydrofuran}

The feed composition for the PVA and silica membranes can be seen in the "Table 1"

The two membranes were studied like PVA (polymeric) membrane and a Silica (ceramic) membrane. The Silica Membrane gave total flux across the membrane was $80 \%$ higher than PVA.

Both membranes are highly selective to water and therefore would be effective in dehydration application. However, the silica membrane does have a 35\% greater selectivity than the PVA membrane. 


\begin{tabular}{|l|l|l|l|}
\hline $\begin{array}{l}\text { Membra } \\
\text { ne type }\end{array}$ & $\begin{array}{l}\text { Flux } \\
(\mathrm{kg} / \mathrm{m} 2 \mathrm{hr})\end{array}$ & $\begin{array}{l}\text { Permeate } \\
\text { Concentration }\end{array}$ & $\begin{array}{l}\text { Selectivit } \\
\mathrm{y}\end{array}$ \\
\hline PVA & 0.153 & 93.2 & 263 \\
\hline Silica & 0.276 & 93.1 & 365 \\
\hline
\end{tabular}

been observed. Variation in first and second portions of the bottom layer is given to control and maintain purity of at least $98 \mathrm{wt} \%$ in the bottoms product. Pervaporation can be considered as a replacement for distillation column where separation is difficult or

Table 1 Membrane performance for feed temperature, permeate pressure, and $w t \%$

\subsubsection{Membrane Performance for Acetonritile}

Membranes process is friendly dehydration process. The dehydration for recycling/purification can be optimized by the use of ceramic membranes is for breaking the azeotrope. Dehydration of acetonitrile from the azeotropic point up to specification: residual water $<0.5-0.1 \%$. The HybridSilica membrane is preferred because of its high flux. The Silica membrane is the best choice for the complete dehydration because of the high selectivity as shown in Table 2.

\begin{tabular}{|l|l|l|l|l|}
\hline $\begin{array}{l}\text { Membra } \\
\text { ne }\end{array}$ & $\begin{array}{l}\text { Hybrid } \\
\text { Silica } \\
\text { Membr } \\
\text { ane }\end{array}$ & $\begin{array}{l}\text { Hybrid } \\
\text { Silica } \\
\text { Permeat } \\
\text { e }\end{array}$ & $\begin{array}{l}\text { Silica } \\
\text { Membra } \\
\text { ne }\end{array}$ & $\begin{array}{l}\text { Silica } \\
\text { Perm } \\
\text { eate }\end{array}$ \\
\hline $\begin{array}{l}\text { Dehydr } \\
\text { ation }\end{array}$ & $10 \mathrm{~m} 2$ & $73 \mathrm{wt} \%$ & $35 \mathrm{~m}^{2}$ & $7 \mathrm{wt} \%$ \\
\hline $\begin{array}{l}\text { Azeotro } \\
\text { pe } \\
\text { Breakin } \\
\text { g }\end{array}$ & $1 \mathrm{~m} 2$ & $61 \mathrm{wt} \%$ & $7 \mathrm{~m}^{2}$ & - \\
\hline
\end{tabular}

Table 2. Dehydration run for both membranes

\section{CONCLUSION}

The separation of azeotrope mixtures, close-boiling mixtures, thermal sensitive, and removing species present in low concentrations became easy. As pervaporation is independent of vapor/liquid equilibria, it can easily remove water from a stream irrespective of the other components present. In Pervaporation low organic and residual water loss has costly. Moreover, pervaporation can be used to improve reactor performance. Since pervaporation is a membrane process, these separations can be combined with the reaction step, resulting in significant improvements in reaction efficiencies, yields, and process economics. To analyze the effect of feed temperature and permeate pressure on pervaporative performance polymeric and ceramic membrane can be used. Flux for both membranes, increased rapidly as the feed temperature was increased, but decreased linearly as permeate pressure was increased. The total flux of the silica membrane was more approachable to temperature and pressure changes than the PVA membrane. For the dehydration, the amount of water in the permeate stream decreased rapidly as the permeate pressure was increased, but increased linearly with increasing temperature for both membranes. It was observed that the selectivity of the PVA membrane was more sensitive to temperature changes than the silica membrane; however the selectivity of the silica membrane was more sensitive to pressure changes than the PVA membrane. Pervaporation is a technology that can be applied to a wide variety of operations in the pharmaceutical and specialty chemical industries where there is high solvent use in manufacturing processes. It has potential to be used as a platform technology for the recovery of solvents from waste streams, as well as solvent reuse schemes. The Combination of distillation and pervaporation as a hybrid process can also be used for separation rather that costly conventional process.

\section{REFERENCES}

[1]. Eva-Katrine Hilmen, Separation of Azeotropic Mixtures: Tools for Analysis and Studies on 
Batch Distillation Operation, November 2000, Norwegian University of Science and Technology Department of Chemical Engineering, pp 32-33.

[2]. Rodriguez-Donis, J. Acosta-Esquijarosa, V. Gerbaud, E. Pardillo-Fondevila, X. Joulia, Separation of $\mathrm{n}$-hexane - ethyl acetate mixtures by azeotropic batch distillation with heterogeneous entrainers, 2005, Chemical Engineering and Processing, Vol 44, pp 131137.

[3]. Mulder, M. 1994. "The use of membrane processes in environmental problems: an introduction". In Membrane Processes in Separation and Purification, Edited by: Crespo, J. G. and Boddeker, K. W. 229-262. Norwell, MA: Kluwer.

[4]. Neto, J. M. and Pinho, M. N. 2000. Mass transfer modeling for solvent dehydration by pervaporation. Separ. Purif. Technol., 18: 151161

[5]. Shah, D., Bhattacharyya, D., Ghorpade, A. and Mangum, W. 1999. Pervaporation of pharmaceutical waste streams and synthetic mixtures using water selective membranes. Environ. Prog., 18: 21-29

[6]. Kujawski, W. and Krajewski, S. R. 2007. Influence of inorganic salt on the effectiveness of liquid mixtures separation by pervaporation. Separ. Purif. Technol., 57: 495-501

[7]. Wijmans, J. G., Baker, R. W. and Athayde, A. L. 1994. Pervaporation: removal of organics from water and organic/organic separations. Membr. Proc. Separ. Purif.,

[8]. Peter D. Chapman, Xiaoyao Tan, Andrew G. Livingston, K. Li, Teresa Oliveira. Dehydration of tetrahydrofuran by pervaporation using a composite membrane. Journal of Membrane Science 2006, 268 (1) , 13-19.

[9]. Vasudevan V. Namboodiri, Leland M. Vane. High permeability membranes for the dehydration of low water content ethanol by pervaporation. Journal of Membrane Science 2007, 306 (1-2) , 209-215.

[10]. Santoshkumar D. Bhat, Tejraj M. Aminabhavi. Zeolite K-LTL-loaded sodium alginate mixed matrix membranes for pervaporation dehydration of aqueous-organic mixtures. Journal of Membrane Science 2007, 306 (1-2)

\section{Cite this article as :}

Isha Meshram, "Study of Novel Separation Technique 'Pervaporation' for Separation of Acetronitrile and Tetrahydrofuran from waste Stream ", International Journal of Scientific Research in Science and Technology (IJSRST), Online ISSN : 2395-602X, Print ISSN : 2395-6011, Volume 8 Issue 4, pp. 698-703, July-August 2021. Available at doi : https://doi.org/10.32628/IJSRST2184108 Journal URL : https://ijsrst.com/IJSRST2184108 